\title{
Sterile empyematous pleural effusion in a patient with systemic lupus erythematosus: a diagnostic challenge
}

\section{Citation}

Kriegel, MA, C Van Beek, A Mostaghimi, and VC Kyttaris. 2009. “Sterile Empyematous Pleural Effusion in a Patient with Systemic Lupus Erythematosus: a Diagnostic Challenge." Lupus 18 (7) (May 11): 581-585. doi:10.1177/0961203309103049.

\section{Published Version}

doi:10.1177/0961203309103049

\section{Permanent link}

http://nrs.harvard.edu/urn-3:HUL.InstRepos:33788472

\section{Terms of Use}

This article was downloaded from Harvard University's DASH repository, and is made available under the terms and conditions applicable to Other Posted Material, as set forth at http:// nrs.harvard.edu/urn-3:HUL.InstRepos:dash.current.terms-of-use\#LAA

\section{Share Your Story}

The Harvard community has made this article openly available.

Please share how this access benefits you. Submit a story.

\section{Accessibility}


Published in final edited form as:

Lupus. 2009 June ; 18(7): 581-585. doi:10.1177/0961203309103049.

\title{
Sterile empyematous pleural effusion in a patient with systemic lupus erythematosus: a diagnostic challenge
}

\author{
MA Kriegel ${ }^{1,2}$, C Van Beek $^{3}$, A Mostaghimi $^{1}$, and VC Kyttaris ${ }^{1}$ \\ ${ }^{1}$ Division of Rheumatology, Beth Israel Deaconess Medical Center, Boston, Massachusetts, USA \\ ${ }^{2}$ Division of Rheumatology, Immunology, and Allergy, Brigham and Women's Hospital, Harvard \\ Medical School, Boston, Massachusetts, USA \\ ${ }^{3}$ Department of Pathology, Beth Israel Deaconess Medical Center, Boston, Massachusetts, USA
}

\begin{abstract}
Herein we present a case of a patient with systemic lupus erythematosus (SLE) and a sterile empyematous pleural effusion, a complication not generally associated with SLE. A discussion of the diagnostic and treatment dilemmas follows the case presentation.
\end{abstract}

\section{Keywords}

empyema; nephritis; systemic lupus erythematosus

\section{Case presentation}

A 26-year-old woman from Cape Verde presented to the Beth Israel Deaconess Medical Centre with severe shortness of breath and chest pain. Several months prior to her presentation, the patient developed fever, progressive dyspnea on exertion, arthralgias, fatigue, weight loss (6 kg over 7 months) and a periorbital rash. One month prior to her presentation, she was found to have large bilateral pleural effusions and acute renal failure. Laboratory evaluation disclosed that she had positive anti-dsDNA antibodies and low complement levels; she was started on $60 \mathrm{mg}$ oral prednisone daily. One week prior to admission to our hospital, she underwent leftsided thoracentesis in a hospital at Cape Verde. The laboratory tests from the pleural fluid demonstrated a glucose level less than $10 \mathrm{mg} / \mathrm{dL}$, lactate dehydrogenase (LDH) of $2054 \mathrm{IU} / \mathrm{L}$ and a pH of 5.0 (Table 1). Bacterial cultures were negative. No antibiotics were administered.

Following this treatment the patient came to the United States for further care. Three days prior to presentation she stopped taking prednisone. Upon presentation to the BIDMC emergency department the patient complained of chest and left flank pain. On physical examination, she was tachycardic, tachypneic and had a temperature of $100.6^{\circ} \mathrm{F}$. She had mild periorbital erythema, dullness to percussion over both lung bases with decreased breath sounds bilaterally and tenderness to palpation over the right flank. She received one tablet of levofloxacin 750 $\mathrm{mg}$ for empiric treatment of pneumonia and was admitted to the hospital. Initial laboratory evaluations are shown in Tables 2 and 3. Chest X-ray and computed tomography revealed left greater than right pleural effusions with loculated air (Figure 1).

(C) The Author(s), 2009.

Correspondence to: Vasileios C Kyttaris, Division of Rheumatology, Beth Israel Deaconess Medical Center, Boston, MA 02115, USA. Email: vkyttari@bidmc.harvard.edu. 
On hospital day one, she underwent thoracentesis of her left-sided effusion and chest tube placement. Pleural fluid laboratory tests and cultures are shown in Table 1. The patient was empirically started on a 14-day course of intravenous Vancomycin $1000 \mathrm{mg}$ every $12 \mathrm{~h}$ and piperacillin-tazobactam $4.5 \mathrm{~g}$ every $8 \mathrm{~h}$ after the procedure. She was also started on prednisone $60 \mathrm{mg}$, hydroxychloroquine $200 \mathrm{mg}$ and lisinopril $5 \mathrm{mg}$ daily. On hospital day two, she underwent thoracentesis of the right pleural effusion, which was consistent with lupus pleuritis (Table 1). On hospital day five, a renal biopsy was performed. Multiple blood cultures remained negative despite continued fevers on broad-spectrum antibiotics. On hospital day six, she underwent a video-assisted thoracoscopy with total pulmonary decortication.

\section{Differential diagnosis}

Pleuritis is the most common manifestation of serositis in patients with systemic lupus erythematosus (SLE). ${ }^{1,2}$ Pleural effusions in patients with SLE can also be secondary to renal failure, pulmonary embolism, infection or congestive heart failure. Lupus pleuritis in SLE is thought to result from immune complex deposition, complement activation and direct binding of anti-dsDNA antibodies to mesothelium. ${ }^{2-4}$ Pleural effusions tend to develop during flares are usually characterised by an exudate with either lymphocytic or neutrophilic predominance, and are often bilateral. ${ }^{1,2}$ On occasion they can be refractory and difficult to treat. ${ }^{5}$ Persistent pleural effusions are at risk for bacterial superinfection potentially leading to the development of empyema. Clinical suspicion of empyema thoracis warrants empiric antimicrobial treatment, especially given that patients with SLE have decreased antimicrobial vigilance and are often treated with immunosuppressive medications. Other causes of empyematous effusions include malignancies, pancreatitis, tuberculosis and rheumatoid arthritis (RA). ${ }^{4,6,7}$ To our knowledge, although pleuritis is a common manifestation of SLE, culture-negative empyema has not been described in patients with SLE.

\section{Infectious workup of pleural effusion}

Pleural fluid with empyematous characteristics including undetectable glucose, $\mathrm{pH}$ less than 7 and very elevated LDH, is highly suggestive of an infection. ${ }^{6,7}$ However, this patient's blood, pleural fluid and tissue cultures were all negative. Broad-spectrum intravenous antibiotics did not abate spiking fevers for several days which would have been expected if the patient had a bacterial infection. It is unlikely that a single dose of levofloxacin 1 day prior to thoracentesis eliminated bacteria from the pleural fluid. It could have possibly influenced mycobacterial growth. Although tuberculosis does not usually present empyematous on pleural fluid sampling, it was certainly considered given the patient's originand highly elevated adenosine deaminase (ADA) in her pleural fluid. However, mycobacterial PCR from pleural fluid and tissue as well as multiple pleural biopsies were unrevealing. In addition, the patient improved slowly on high dose immunosuppression (see later), which should have exacerbated tuberculosis.

\section{ADA elevation in pleural fluid}

The enzyme ADA is involved in differentiation of lymphoid cells. ${ }^{8}$ It is most abundant in lymphocytes, predominantly activated $\mathrm{T}$ cells (although the isoenzyme 2 is found mostly in monocytes/macrophages). ${ }^{8}$ Total ADA levels greater than $70 \mathrm{IU} / \mathrm{L}$ in pleural fluid samples are highly suggestive of tuberculosis but can also be seen in bacterial empyematous effusions. ${ }^{8}$ Other aetiologies of high pleural fluid ADA levels include malignancies, various other infections (including fungal) and RA. ${ }^{8}$ None of these could be established as a cause in this patient. Importantly, an extensive workup for tuberculosis was negative as mentioned earlier. ADA levels in pleural fluid from patients with SLE have not yet been thoroughly studied. One report demonstrated levels below $50 \mathrm{IU} / \mathrm{L}$ in three patients with SLE (mean of $33.3 \mathrm{IU} / \mathrm{L}$ ). ${ }^{9}$ Another study established ADA levels around $15 \mathrm{IU} / \mathrm{L}$ in four SLE patients with patients when 
examining the value of ADA in the diagnosis of tuberculous pleural effusions in young women in a region with high prevalence of tuberculosis. ${ }^{10} \mathrm{We}$ did not measure ADA in our patient's exudative (but non-empyematous), right-sided pleural effusion. We speculate that levels would have been considerably lower than in her highly abnormal left-sided effusion with empyematous characteristics and an ADA level above 100 IU/L. Remarkably, the ADA level in her left-sided effusion was only $4.3 \mathrm{IU} / \mathrm{L} 1$ week prior to admission when examined in a hospital at Cape Verde. Little is known about sequential ADA levels over time in pleural fluids from patients with infectious or autoimmune diseases. Ongoing research on ADA and its isoenzymes (ADA-1 and ADA-2) will hopefully further clarify the usefulness of measuring ADA in various infectious and rheumatic diseases.

\section{Clinical diagnosis}

SLE with lupus nephritis and sterile empyematous pleural effusion.

\section{Pathologic discussion}

Histological examination of the pleural tissue revealed extensive granulation tissue with associated haemorrhage and fibrinopurulent exudates (Figure 2). Mixed inflammation comprised predominantly of neutrophils and lymphocytes was present without granulomata. Special stains (including Gomori-methenamine-silver and gram) performed were negative for microorganisms. PCRs for Mycobacterium tuberculosis done on pleural tissue were all negative.

The renal biopsy specimen contained 25 glomeruli all showing moderate mesangial proliferation and markedly thickened peripheral capillary loops with global and diffuse spike formation. In addition, 10 glomeruli showed segmental endocapillary proliferation and three had cellular crescents (Figure 2). Rare "hyaline thrombi" were also seen. There was minimal interstitial fibrosis and tubular atrophy. Vascular structures were unremarkable.

Immunofluorescence studies demonstrated granular immune complex deposition within all glomeruli involving peripheral capillary walls and the mesangium. Several features of lupus nephritis were seen including presence of all immunoreactants including $\operatorname{IgG}, \operatorname{IgA}, \operatorname{IgM}, \mathrm{C} 3$, kappa, lambda and C1q ('full-house' staining) within the glomeruli; immune complex deposition (IgG predominantly) within vessels and tubular basement membranes; and staining of tubular epithelial nuclei with IgG ('tissue ANA'). Ultrastructural examination revealed numerous electron dense deposits without substructure in the subepithelial, subendothelial and mesangial locations. Tubular reticular structures, also typical of lupus nephritis were noted.

\section{Anatomical diagnosis}

1. Lupus nephritis, ISN/RPS Classification: mixed Class III (a) Focal Lupus Nephritis and V Membranous.

2. Fibrino-purulent haemorrhagic pleuritis without granuloma formation.

\section{Treatment course}

Prednisone was continued at $60 \mathrm{mg}$ daily orally. Lisinopril was increased to $10 \mathrm{mg}$ daily but had to be discontinued during a hypotensive episode after her video-assisted thoracoscopy. She required transfer to the intensive care unit and brief administration of intravenous fluids. The patient was started on mycophenolate mofetil (MMF) $500 \mathrm{mg}$ twice daily 2 weeks after admission when renal biopsy results revealed Class III/V lupus nephritis (Figure 2). Over the following week, her symptoms improved significantly. She completed an empiric 14-day course of intravenous vancomycin and piperacillin-tazobactam. Oral prednisone was slowly tapered to $35 \mathrm{mg}$ daily during this hospital stay as MMF was increased to $1500 \mathrm{mg}$ twice daily. 
The patient was discharged on prednisone $35 \mathrm{mg}$ daily and MMF $1500 \mathrm{mg}$ twice daily with resolving pleural effusions, haemodynamic stability and resolution of urinary cellular casts but persistent nephritic range proteinuria.

\section{Discussion of treatment for lupus nephritis}

Induction therapy for lupus nephritis with MMF is an attractive alternative to intravenous pulse cyclophosphamide following the NIH regimen, as suggested by recent clinical trials comparing these drugs with concomitant moderate- to high-dose glucocorticoid treatment. ${ }^{11-14} \mathrm{MMF}$ is associated with less infectious complications than cyclophosphamide. ${ }^{11-14}$ MMF improves quality of life as perceived by patients when compared with cyclophosphamide. ${ }^{11,15}$ Standard treatment with cyclophosphamide also requires frequent clinic visits for intravenous infusions which is inconvenient. On the basis of its improved safety profile over cyclophosphamide and at least equal efficacy, some investigators even suggest MMF as first-line induction therapy for proliferative lupus nephritis. ${ }^{11}$ Our patient was certainly an excellent candidate for MMF given her preserved renal function, non-Caucasian or Asian background and young age with possible future pregnancy wishes. ${ }^{13}$ Patients with different patient characteristics and more severely impaired renal function might still have been preferably treated with intravenous cyclophosphamide. Future studies and longer follow-up of this heterogeneous patient population will hopefully confirm the evolving advantages of MMF in the induction phase for lupus nephritis over more traditional, cytotoxic regimens. Our patient remains in remission on $1500 \mathrm{mg}$ of MMF twice daily and currently $12.5 \mathrm{mg}$ of daily oral prednisone (seven months after discharge). Further studies are also needed to address dosing and duration of glucocorticoids which remain an integral part of induction regimens and are a significant contributor to complications and adverse events.

\section{Final remarks on sterile empyematous pleural effusions}

To our knowledge, culture-negative empyematous effusions have not been reported in patients with SLE. However, culture-negative empyema has been described to occur relatively frequently in children and is thought to be due to prior antibiotic exposure in most cases. ${ }^{16}$ Highly sensitive Streptococcus pneumoniae is likely rapidly eliminated from the pleural fluid by the bacteriocidal action of cell wall inhibitors like penicillins. It is plausible that this can occur after only a brief course of antibiotics prior to fluid sampling. 16S ribosomal DNA PCR has been shown to increase the yield in paediatric culture-negative empyema. ${ }^{16}$ Bacterial PCR may have been useful in this case to confirm a suspected infectious process.

On the other hand, sterile empyematous pleural effusions have been reported in RA, pancreatitis and malignancy as mentioned earlier. ${ }^{4,6,7}$ Our patient certainly had systemic and local immunological activity consistent with active SLE given her systemic manifestations and very high ANA levels with low complement in both serum and pleural fluid. Measurement of pleural fluid ANA is usually not recommended as it contributes little additional information to serum levels that have been shown to correlate with pleural fluid levels. ${ }^{17}$ However, absence of ANAs in the patient's left-sided pleural effusion would have excluded lupus-related pleuritis and supported an infectious process. ${ }^{17}$

It remains unclear if the left-sided effusion was ever infected. Differentiation between infectious and purely inflammatory processes remains challenging in patients with autoimmune or autoinflammatory diseases, especially as infections can trigger flares in some cases. Improvements in the molecular detection of microbes as well as more specific tests for involvement of the various organs in systemic autoimmunity will be helpful in reducing these uncertainties in the future. 


\section{Acknowledgements}

This work was supported by the National Institute of Arthritis, Musculoskeletal and skin diseases grant No 1 K23 AR055672-01.

\section{References}

1. Swigris JJ, Fischer A, Gillis J, Meehan RT, Brown KK. Pulmonary and thrombotic manifestations of systemic lupus erythematosus. Chest 2008;133:271-280. [PubMed: 18187752]

2. Man BL, Mok CC. Serositis related to systemic lupus erythematosus: prevalence and outcome. Lupus 2005;14:822-826. [PubMed: 16302677]

3. Guo H, Leung JC, Chan LY, Chan TM, Lai KN. The pathogenetic role of immunoglobulin G from patients with systemic lupus erythematosus in the development of lupus pleuritis. Rheumatology (Oxford) 2004;43:286-293. [PubMed: 14623950]

4. Balbir-Gurman A, Yigla M, Nahir AM, Braun-Moscovici Y. Rheumatoid pleural effusion. Semin Arthritis Rheum 2006;35:368-378. [PubMed: 16765714]

5. Breuer GS, Deeb M, Fisher D, Nesher G. Therapeutic options for refractory massive pleural effusion in systemic lupus erythematosus: a case study and review of the literature. Semin Arthritis Rheum 2005;34:744-749. [PubMed: 15846590]

6. Porcel JM, Light RW. Diagnostic approach to pleural effusion in adults. Am Fam Physician 2006;73:1211-1220. [PubMed: 16623208]

7. Light RW. Clinical practice. Pleural effusion. N Engl J Med 2002;346:1971-1977. [PubMed: 12075059]

8. Gopi A, Madhavan SM, Sharma SK, Sahn SA. Diagnosis and treatment of tuberculous pleural effusion in 2006. Chest 2007;131:880-889. [PubMed: 17356108]

9. Pettersson T, Klockars M, Weber T. Pleural fluid adenosine deaminase in rheumatoid arthritis and systemic lupus erythematosus. Chest 1984;86:273-274. [PubMed: 6744969]

10. Valdes L, Alvarez D, San Jose E, et al. Value of adenosine deaminase in the diagnosis of tuberculous pleural effusions in young patients in a region of high prevalence of tuberculosis. Thorax 1995;50:600-603. [PubMed: 7638798]

11. Chan TM. Mycophenolate mofetil in the treatment of lupus nephritis-7 years on. Lupus 2008;17:617621. [PubMed: 18625633]

12. Ginzler EM, Dooley MA, Aranow C, et al. Mycophenolate mofetil or intravenous cyclophosphamide for lupus nephritis. N Engl J Med 2005;353:2219-2228. [PubMed: 16306519]

13. Houssiau FA, Ginzler EM. Current treatment of lupus nephritis. Lupus 2008;17:426-430. [PubMed: 18490421]

14. Schieppati A, Remuzzi G. Novel therapies of lupus nephritis. Curr Opin Nephrol Hypertens 2008;17:156-161. [PubMed: 18277148]

15. Tse KC, Tang CS, Lio WI, Lam MF, Chan TM. Quality of life comparison between corticosteroidand-mycofenolate mofetil and corticosteroid- and-oral cyclophosphamide in the treatment of severe lupus nephritis. Lupus 2006;15:371-379. [PubMed: 16830884]

16. Le Monnier A, Carbonnelle E, Zahar JR, et al. Microbiological diagnosis of empyema in children: comparative evaluations by culture, polymerase chain reaction, and pneumococcal antigen detection in pleural fluids. Clin Infect Dis 2006;42:1135-1140. [PubMed: 16575731]

17. Porcel JM, Ordi-Ros J, Esquerda A, et al. Antinuclear antibody testing in pleural fluid for the diagnosis of lupus pleuritis. Lupus 2007;16:25-27. [PubMed: 17283581] 

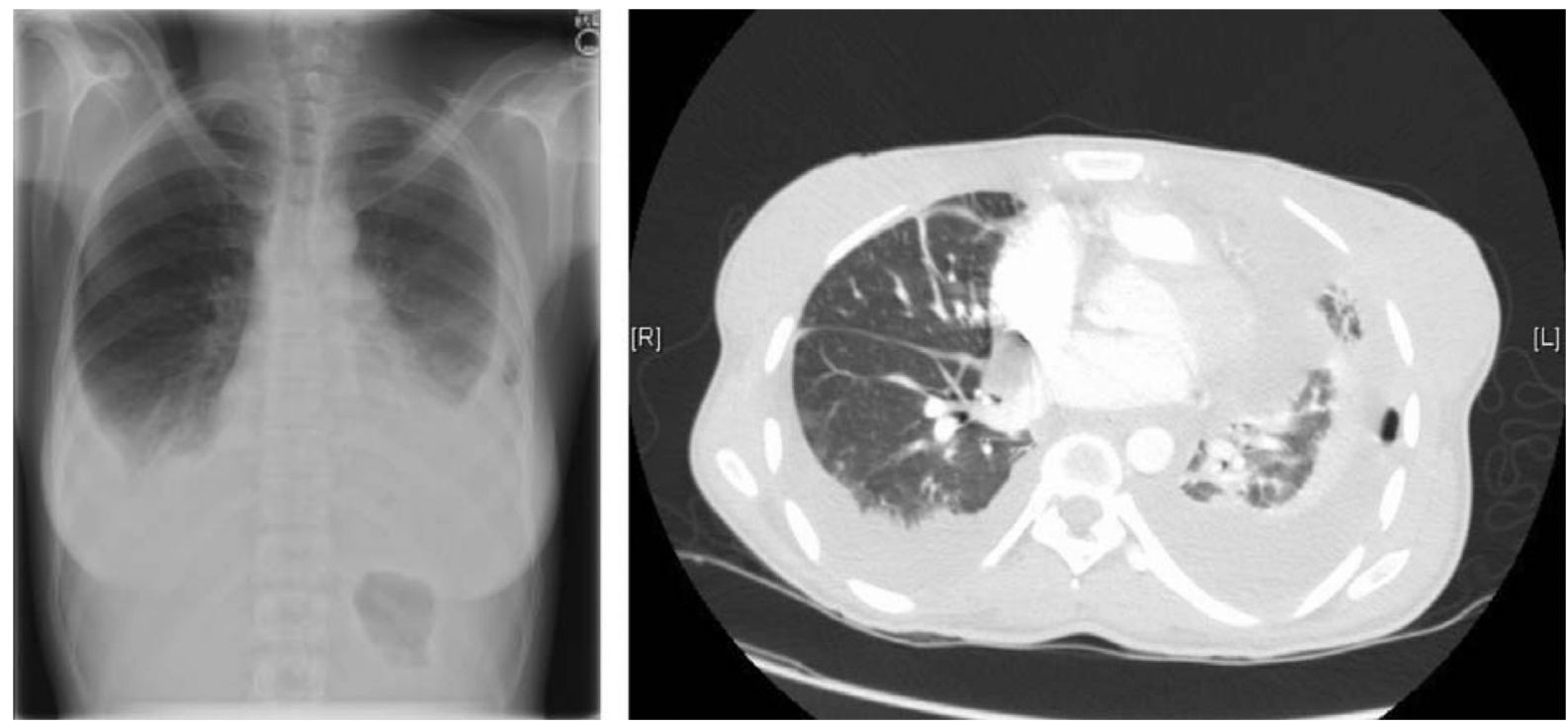

Figure 1.

Chest X-ray and contrast-enhanced computed tomography of the chest. Chest X-ray demonstrates moderate-sized bilateral pleural effusions, left greater than right, with associated atelectasis and left-sided loculation. Apical pleural thickening is noted bilaterally. Computed tomography demonstrates large, bilateral pleural effusions and small pericardial effusion. Multiple foci of air within the left-sided pleural effusion are noted. No rim enhancement present. 

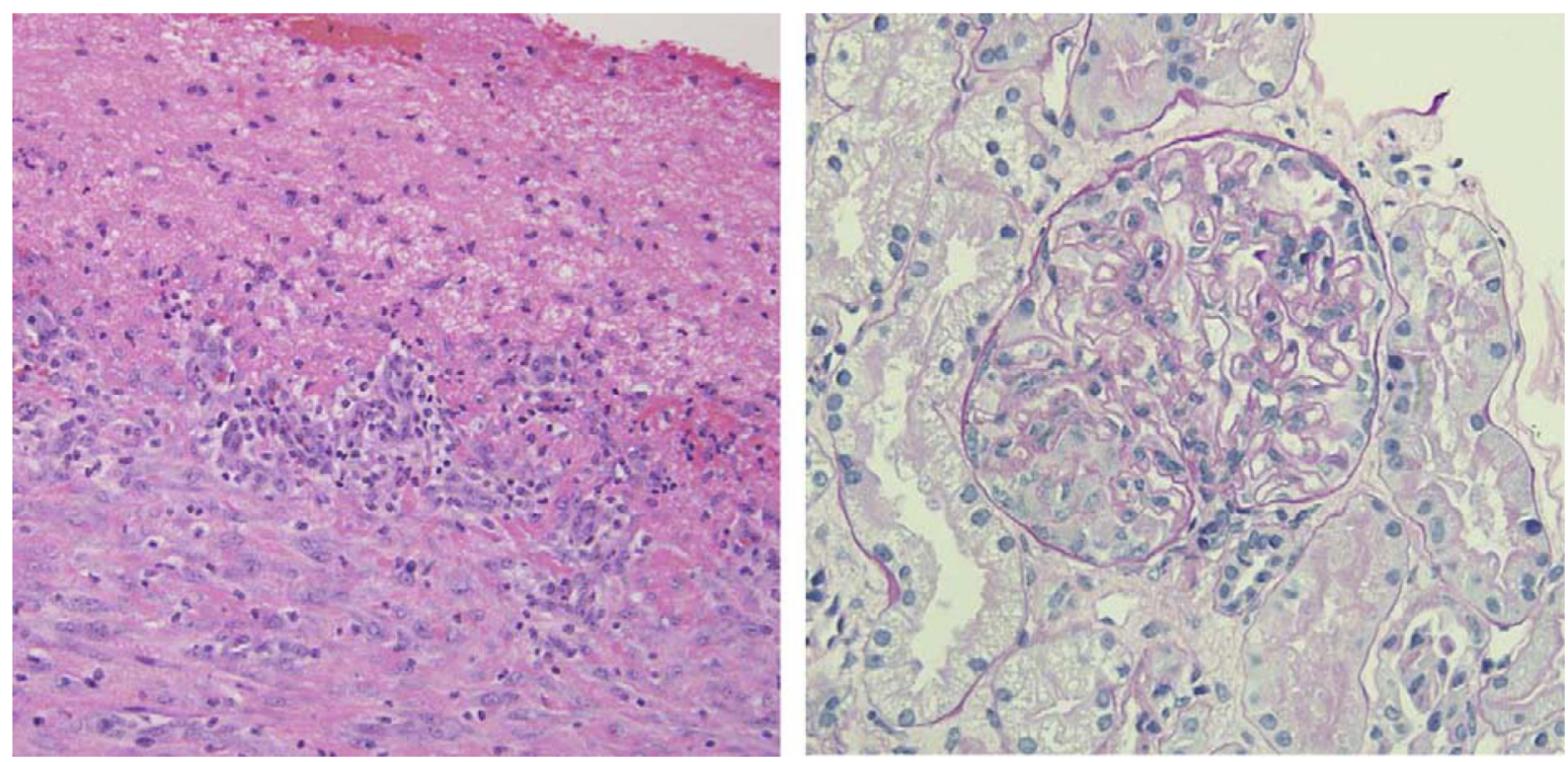

Figure 2.

Microscopic images from pleural (left image) and renal (right image) biopsies. Pleural tissue histology reveals extensive granulation tissue with associated haemorrhage and fibrinopurulent exudates. The PAS stain from the renal biopsy shows a glomerulus with a cellular crescent and thickened peripheral capillary walls consistent with Class III/V lupus nephritis. 
Pleural fluid results

Table 1

\begin{tabular}{|c|c|c|c|}
\hline Test (units) & $\begin{array}{l}\text { Left-sided effusion }^{a}(1 \\
\text { week prior to admission) }\end{array}$ & $\begin{array}{l}\text { Left-sided effusion (on } \\
\text { admission) }\end{array}$ & $\begin{array}{l}\text { Right-sided effusion ( } 1 \\
\text { day after admission) }\end{array}$ \\
\hline Volume (mL) & - & 425 & 620 \\
\hline White blood count (cells $/ \mu \mathrm{L})$ & - & 11,250 & 1400 \\
\hline Red blood cells (cells $/ \mu \mathrm{L}$ ) & - & 2500 & 7250 \\
\hline Neutrophils (\%) & - & 91 & 74 \\
\hline Lymphocytes (\%) & - & 1 & 9 \\
\hline Monocytes (\%) & - & 2 & 17 \\
\hline Macrophages (\%) & - & 6 & 0 \\
\hline $\mathrm{pH}$ & 5.0 & 6.83 & 7.24 \\
\hline Total protein $(\mathrm{g} / \mathrm{dL})^{b}$ & 3.1 & 4.5 & 4.1 \\
\hline Glucose (mg/dL) & $<10$ & 0 & 210 \\
\hline $\mathrm{LDH}(\mathrm{IU} / \mathrm{L})^{a}$ & 2054 & 9850 & 417 \\
\hline Antinuclear antibodies & - & $1: 1280$ & $1: 1280$ \\
\hline Total complement (U/mL) & - & $<10$ & Not done \\
\hline Gram-stain and cultures & Negative & Negative & Negative \\
\hline Malignant cells & - & Negative & Negative \\
\hline Adenosine deaminase (U/L) & 4.3 & 105.0 & Not done \\
\hline Mycobacterial PCR & - & Negative & Negative \\
\hline
\end{tabular}

${ }^{a}$ Pleural fluid laboratory values from outside hospital at Cape Verde. - denotes that data not available.

${ }^{b}$ Serum protein level was $6.9 \mathrm{~g} / \mathrm{dL}$ and serum LDH level was $198 \mathrm{IU} / \mathrm{L}$. 
Table 2

Results of blood and urine tests on admission

\begin{tabular}{|c|c|c|}
\hline Test (units) & Value & Normal range \\
\hline Hematocrit (\%) & 30.1 & $36-48$ \\
\hline Haemoglobin (g/dL) & 9.8 & $12.0-16.0$ \\
\hline White blood cells (cells $/ \mu \mathrm{L}$ ) & 8000 & $4000-11,000$ \\
\hline \multicolumn{3}{|l|}{ Differential count $(\%)$} \\
\hline Neutrophils & 71.7 & $50-70$ \\
\hline Lymphocytes & 23.2 & $18-42$ \\
\hline Monocytes & 4.1 & $2-11$ \\
\hline Eosinophils & 0.3 & $0-4$ \\
\hline Basophils & 0.6 & $0-2$ \\
\hline Platelets (cells $/ \mu \mathrm{L}$ ) & 294,000 & $150,000-440,000$ \\
\hline Erythrocyte sedimentation rate $(\mathrm{mm} / \mathrm{h})$ & 105 & $0-20$ \\
\hline C-reactive protein (mg/L) & 122 & $0-5$ \\
\hline Urea nitrogen $(\mathrm{mg} / \mathrm{dL})$ & 40 & $6-20$ \\
\hline Creatinine (mg/dL) & 0.9 & $0.4-1.1$ \\
\hline \multicolumn{3}{|l|}{ Urinalysis } \\
\hline Red blood cells (cells/hpf) ${ }^{a}$ & $3-5$ & $0-2$ \\
\hline White blood cells (cells/hpf) & $11-20$ & $0-6$ \\
\hline $\mathrm{pH}$ & 5.0 & $5-8$ \\
\hline Protein $(\mathrm{mg} / \mathrm{dL})$ & $>500$ & Negative \\
\hline Glucose (mg/dL) & Negative & Negative \\
\hline
\end{tabular}

$a_{\text {hpf, high power field. }}$ 
Table 3

Serologic test results

\begin{tabular}{llc}
\hline Test (units) & Value & Normal range \\
\hline Antinuclear antibodies (titre) & $1: 1280$ (speckled pattern) & $<1: 80$ \\
Anti-dsDNA antibodies (U/mL) & $1: 80$ & Negative \\
Rheumatoid factor (IU/mL) & 15 & $0-14$ \\
C1q (mg/dL) & $<3.6$ & $5.0-8.6$ \\
C3 (mg/dL) & 31 & $90-180$ \\
C4 (mg/dL) & 5 & $10-40$ \\
Smith antibody (units) & $>8$ & $<1$ \\
RNP antibody (units) & $>8$ & $<1$ \\
SS-A and SS-B antibodies (units) & $>8$ & $<1$ \\
\end{tabular}

